\title{
Do Pensamento às Palavras \\ Instrumento metodológico para a análise dos discursos
}

\section{Of the Thought to the Words \\ Instruments for the analysis of the speeches}

Luiz Augusto F. Rodrigues ${ }^{1}$

\section{Resumo}

Fundamentos teóricos de proposta metodológica de análise do discurso que toma por base contribuições da psicanálise lacaniana. Discurso, representação e ideologia.

Análise do discurso

Imaginário

[lacaniano]

\section{Abstract}

"Of the thought to the words" is founded in theoretical beddings of proposal methods of analysis of the speech that takes for base contributions of the lacanian psychoanalysis. Speech, representation and ideology.
Key words:

Applied Linguistics

The modernist

tradition

Position "on the

border"
Este ensaio faz parte das reflexões contidas no livro Universidade e a fantasia moderna: a falácia de um modelo espacial único publicado pela Editora da Universidade Federal Fluminense em 2001. São reflexões oriundas de minha tese de doutorado em História, defendida nessa mesma Universidade. Graduado em Arquitetura e Urbanismo, minhas preocupações se direcionam a diferentes discursos, em especial os discursos sobre a cidade.

Pensar sobre o indivíduo em seu contexto cultural é inseri-lo num campo de paradigmas transdisciplinares que busquem romper as barreiras de um conhecimento compartimentado. Hegel já nos apontava que mesmo na razão universal o indivíduo não perde sua referência unitária (ZIZEK, 1991). Por mais que se privilegie o plano da percepção sensível (o campo da experiência visual e imagética), os meios de comunicação de massa têm forte apelo significativo a partir das construções discursivas.

O caminho aberto por Marx, e seguido por outros teóricos, vê a ideologia como um fator de dominação. Gramsci amplia os horizontes, tratando a ideologia como componente da realidade e, como tal, abarcando todas as classes. Em Althusser vamos encontrar os dois caminhos: enquanto fator de dominação (efeito de ilusão) e enquanto visão de mundo (efeito de alusão). Se, por um lado, a trajetória teórica apresentada já apontava elementos inconscientes, em todos eles o

\footnotetext{
${ }^{1}$ Professor do Departamento de Arte da Universidade Federal Fluminense Coordenador do LABAC-UFF / Laboratório de Ações Culturais UFF - Instituto de Artes e Comunicação Social
} 
inconsciente foi tratado como contradição ou ambivalência. Os estudos lacanianos, aprofundados por Slavoj Zizek, na direção de compreender como se estrutura a ideologia, vão contribuir diretamente para a correlação entre ideologia e inconsciente, tendo na experiência linguística um eficaz elemento de conhecimento (entendimento) de ambos.

Parece-me assim, ser impossível retirar da realidade a carga ideológica que a compõe. Como proceder, então, à análise de determinada realidade? Como interpretar suas relações? Podemos aproximarmo-nos de uma realidade pura? Ela existe?

Talvez o caminho não deva ser propriamente esse. $\mathrm{O}$ desafio encontra-se em identificar a maior e mais complexa gama de representações, ou antes, as variações de representações de uma mesma realidade, identificando-se os elementos dominantes e os dominados, e neles - num sentido hegeliano suas contradições e suas oposições.

Na concepçãomarxista, argumentaZizek, atribui-se à ideologia uma "certa ingenuidade constitutiva: a ideologia desconhece suas condições, suas pressuposições efetivas, e seu próprio conceito implica uma distância entre o que efetivamente se faz e a 'falsa consciência' que se tem disso [eles não sabem o que fazem mas o fazem assim mesmo]" (1992: 59).

Essa concepção é ampliada por autores da Escola de Frankfurt na análise crítico-ideológica, que tem como finalidade "detectar, por trás da universalidade aparente, a particularidade de um interesse que destaca a falsidade da universalidade em questão: o universal, na verdade, está preso ao particular, é determinado por uma constatação histórica concreta" (Idem).

O estudo de Bakhtin (1986) aponta para a potencialidade da análise de um momento histórico a partir dos discursos nele produzidos. Pela linguagem, apreende-se a síntese do sistema ideológico. Tanto o que se encontra mais cristalizado, quanto o que de novo anuncia-se.

$\mathrm{O}$ autor dá um passo à frente, em relação às correntes linguísticas, ao incorporar à linguagem fatores da realidade concreta, das representações, e do psiquismo individual. Incorpora ação, pensamento e emoção, porém ele próprio afirma que “a língua não é o reflexo das hesitações subjetivo-psicológicas, mas das relações sociais estáveis dos falantes" (BAKHTIN, 1986: 147), ou seja, Bakhtin parece incorporar apenas as emoções conscientes, deixando de fora as emoções que não afloram à consciência do falante, mas que podem também ser percebidas por outrem em sua fala. "Assim, nas formas de transmissão do discurso, a própria língua reage à personalidade como suporte da palavra" (1986: 188); só que além de reagir, ela também pode deixar escapar coisas que são inconscientes. Os atos falhos, os lapsos,..., que Freud já nos apontava.

Jacques Lacan nos dá subsídios para flagrar a ideologia através da linguagem, pois desloca a ênfase dada ao sentido. Para ele, o importante não é o significado, mas o significante (a parte material do signo); e que é na relação entre a metáfora e a metonímia que residem suas essências:

Com isso, o autor quer dizer que o desejo inconsciente, que supostamente constituiria o núcleo mais oculto, escapa justamente na tentativa de disfarçar esse núcleo. Escapa, torna-se exterior, só que "disfarçado", e aí entram os mecanismos de deslocamento e condensação presentes nas metáforas e metonímias.

Por isso, devemos ir do pensamento às palavras (que é uma expressão do próprio Lacan): fugir da tentativa de entender o que está oculto no pensamento, e sim aquilo que pode ser aclarado a partir das palavras. Entender o processo pelo qual o sentido oculto disfarçouse através de determinada(s) forma(s).

Podemos amparar-nos também em Michel Foucault (1996) quando propõe uma análise a partir das relações do poder com o saber e destaca as aceitações ou negações de discursos como exclusões (ou não) a partir das quais é exercido o poder, na tentativa de dominar seu acontecimento aleatório. Uma dessas funções de exclusão discursiva é a interdição que determina o que pode ou não ser dito.

A teoria lacaniana aponta-nos que o desejo (de poder, de saber, ou qualquer outro) apresenta-se de forma irrestrita. A estrutura de formação do indivíduo, e inerente a ele, assenta-se, no limite, no desejo de apoderar-se do todo. Como o todo é inalcansável, resta-nos sempre o sentimento de falta. Esse sentido de 
falta que estrutura o imaginário (o desejo, ou o núcleo do desejo) disfarça-se recorrentemente, escapando independentemente da censura consciente. Escapa justamente na tentativa de realização de um desejo maior (e anterior); escapa-nos como mecanismo de superação da angústia de tudo querer.

$\mathrm{O}$ que procurarei metodologicamente fazer, e consubstanciado pelas reflexões anteriores, é analisar as produções discursivas a partir de três níveis: o claramente dito (cuja veracidade é facilmente confrontável com a simples constatação da realidade); o não dito (o ideológico não evidenciado no discurso, mas resgatável -com o respaldo da Históriaenquanto intenção velada); e o interdito (ou seja, as fantasias "proibidas" de aflorar conscientemente, mas que escapam através dos mecanismos da própria língua -as metáforas e metonímias) (RODRIGUES, 1998s).

E busco sempre como pano de fundo a constituição da Identidade.

A identidade cria amarras no indivíduo (no sujeito) as quais permitem que ele persiga caminhos plurais mas com direção clara, de modo que não fique "voando sem rumo". Sem identidade, o indivíduo, muitas vezes, fica sem clareza de seus desejos e aspirações, sendo, desse modo, sujeito a que guiem suas motivações externamente.

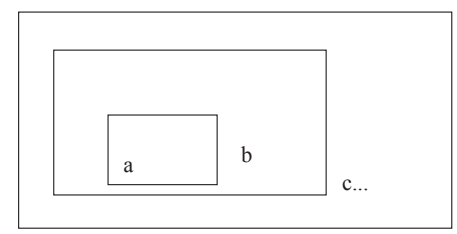

$a=$ a estrutura do sujeito lacaniano

$b=$ os arquétipos jungianos

$c=$ as características singularizadas (padrões nacionais, diferenças culturais, diferenças de gênero, ...

O núcleo duro da identidade não pressupõe subtrair as singularidades em favor dos universais. Seria buscar as diferenças no interior de certas invariantes. Essas diferenças, por sua vez, são dadas não apenas por variantes individualizadas, mas também por contextos culturais e históricos particularizados.

Sugestão gráfica para a Identidade, segundo subconjuntos: onde a e b são comuns a todos os indivíduos, c, d, e... são próprios de determinados grupos.

As linguagens estruturam nossa percepção e posicionamento no mundo. Então, através dos discursos podem-se flagrar indícios de como a realidade está sendo social e particularmente construída. Sejam os discursos verbais, sejam os não verbais.

Meu propósito final é o estudo da cidade e das práticas culturais.

A cidade pesquisada através: do discurso jornalístico (e as construções identitárias que ele produz); do discurso pessoal (e possíveis constatações da incorporação de um discurso técnico "competente"); do discurso não verbal (através das imagens veiculadas e através dos usos e formas de apropriação dos espaços); da identificação de alterações no uso (e/ou consumo) da cidade em face das novas tecnologias de informação e meios de comunicação que operam sobre as expectativas e percepções dos usuários da cidade; do reconhecimento dos sentidos de pertencimento através dos quais uma sociedade pode reconhecer-se.

Com base nos estudos do alemão Peter Sloterdijk, Zizek alerta-nos de que nem mesmo essa análise crítica responde devidamente a esta questão, pois a ideologia funciona cada vez mais envolta por uma "razão cínica": eles sabem muito bem o que fazem, e o fazem assim mesmo; ou seja, estamos perfeitamente conscientes da falsidade que há por trás da universalidade ideológica, mesmo assim não renunciamos a essa universalidade.

A partir desses enfoques, o autor destaca o papel da fantasia, pois “o 'cínico', que 'não acredita nisso', que sabe muito bem da inutilidade das proposições ideológicas, desconhece, no entanto, a fantasia que estrutura a própria 'realidade' social' (ZIZEK, 1992: 61).

Como proceder a análise da ideologia levando em conta o imaginário, as fantasias inconscientes?

Os estudos, entre outros, de Cerqueira Filho ilustram-nos o caminho possível: "A repetição de certos significantes de que a repressão se apoderou ou ocultou, isto é, reprimiu, é o que deve ser interpretado" (1988: 27), pois em todo ato de fala, o "discurso 
consciente, atividade da imaginação, se deixou penetrar sob uma forma velada, incompreensível, pelo discurso inconsciente" (1988: 26). Lacan reafirma colocações já presentes em Freud de que, como maneira de revelar o inconsciente, podemos utilizar os sintomas que afloram na linguagem, nas figuras de metáfora e metonímia.

Zizek desloca conceitualmente a Ideologia. Ela não mascara a realidade e sim o real do desejo (da fantasia), ou seja, a ideologia é uma esfera intrínseca da realidade. O autor aborda a questão segundo a tese lacaniana ao dizer que sempre existe um "núcleo sólido", um "resto" que persiste (o Real é concebido como aquilo que "sempre retorna ao mesmo lugar"), e que a única maneira de nos aproximarmos desse "núcleo sólido do Real" é através do sonho; o mesmo que acontece com o "sonho ideológico". "A única maneira de romper com o poder de nosso sonho ideológico é confrontar o Real de nosso desejo que se anuncia nesse sonho" (ZIZEK, 1996: 325).

\begin{abstract}
A ideologia (...) é uma construção de fantasia que serve de esteio à nossa própria "realidade": uma "ilusão" que estrutura nossas relações sociais reais e efetivas e que, com isso, mascara um insuportável núcleo real impossível (...). A função da ideologia não é oferecer-nos uma via de escape de nossa realidade, mas oferecer-nos a própria realidade social como uma fuga de algum núcleo real traumático (ZIZEK, 1996: 323).
\end{abstract}

O autor aponta que, já na década de 50, Roland Barthes (em Mitologias) propunha a noção de ideologia como "naturalização da ordem simbólica", querendo com isso alertar para um tipo de percepção da realidade que "reifica os resultados dos processos discursivos em propriedades da 'coisa em si' " (ZIZEK, 1996: 16).

Através do sonho ideológico, a percepção da realidade é estruturada antecipadamente: percebemos o mundo da maneira pela qual somos levados a percebê-lo.

Para Zizek, há uma "oposição entre a ideologia como universo de vivência 'espontânea' (...) e a ideologia como uma máquina radicalmente não espontânea, que distorce de fora para dentro a autenticidade da nossa experiência de vida" (1996: 24).

Daí a importância da incorporação das ideias lacanianas para a interpretação de nossa realidade social, pois a realidade mascara o real do desejo. Observem que há aí uma inversão relevante, pois não é a realidade que é mascarada pelo desejo, e sim a realidade é que mascara o desejo. E esse núcleo recalcado do desejo "escapa", tanto através do mecanismo do sonho, quanto através do mecanismo da linguagem.

Por Jacques Lacan, temos a fantasia articulada à estrutura da repetição -desejo não satisfeito que se manifesta de maneira recorrente- e que o modo de nos aproximarmos do núcleo desse desejo é através das metáforas e metonímias (passar do pensamento às palavras).

Por concordar com o autor, sou levado a me contrapor às análises que Umberto Eco faz sobre a metáfora como expressão de um tempo:

Quanto mais original tiver sido a invenção metafórica, tanto mais sua geração terá violado cada um dos hábitos retóricos precedentes. É difícil produzir uma metáfora inédita com base em regras já adquiridas, e toda e qualquer tentativa no sentido de prescreverem-se regras para produzir uma in vitro fará com que se gere uma metáfora morta, ou excessivamente banal (ECO, 1995: 113).

Sou levado a discordar, pois, como veremos a seguir, as metáforas -assim como as metonímias- permitem, por meio de seus significantes (e não de seus significados imediatos do texto), aproximarmo-nos das fantasias inconscientes do "falante", não tendo necessariamente o vínculo que Eco tenta estabelecer.

Cabe, neste momento, conceituar termos e expressões que apresentam significações específicas, quando utilizadas neste trabalho.

Metáfora e Metonímia são figuras de linguagem definidas, de modo singular, por, respectivamente: comparação; nomear uma 
coisa por outra, tomando a parte pelo todo ou o todo pela parte.

Roman Jakobson será o linguista que melhor subsidiará a reflexão lacaniana, pois tira das metáforas e metonímias seus laços estritos à gramática, ligando-as relacionalmente uma a outra, e apontando-as como um dos princípios básicos do código verbal:

metáfora e metonímia são, assim, as expressões mais condensadas dos processos desenvolvidos sob as relações de similaridade e de contiguidade. Ou ainda, são os resultados explícitos de démarches inconscientes, ancorados nos dois eixos básicos presentes no código expressional humano, verbal ou não verbal (KATZ, DORIA, LIMA: 1971, p. 208).

Charles Peirce, lógico da virada do século XIX para o XX e fundador da teoria dos signos, verá, também, a metáfora como transferência do nome pela similaridade dos sentidos, e a metonímia como transferência pela contiguidade dos sentidos.

Lacan, no entanto, desloca a ênfase dada ao sentido. Para ele o importante não é o significado, mas o significante (a parte material do signo); e que é na relação entre a metáfora e a metonímia que residem suas essências:

- metáfora: substituição do significante recalcado, relegado ao nível de significado para aquele que o representa;

- metonímia: combinação de significantes onde o discurso manifesto, suprimindo o essencial, compõe sua unidade tranquilizadora, posto que ilegível.

\section{Consideremos as definições de Ducrot \&} Todorov para depois dar a palavra ao próprio Lacan. Segundo esses autores, para Lacan:

a condensação é uma metáfora, em que se diz para o sujeito o sentido recalcado do seu objeto, e: o deslocamento é uma metonímia: onde se marca que é o desejo, desejo de outra coisa que falta sempre. Porque o que implica estas duas fórmulas é que não chega, para fazer um tropo, pôr uma palavra no lugar de outra em virtude dos seus significados respectivos. A metáfora, muito mais precisamente, é o aparecimento numa cadeia significante dada de um significante vindo de uma outra cadeia,
(...). Quanto à metonímia, remete menos de um termo para outro, do que marca a função essencial da falta no interior da cadeia significante: a conexão dos significantes que permitem operar 'a transferência' daquilo que não deixa de faltar num discurso, ou seja, um prazer definitivo (DUCROT, TODOROV, 1974: 416-417).

Condensação e deslocamento são conceitos que Lacan toma de Freud e associaos, respectivamente, à metáfora e à metonímia, embora Lacan não as considere isoladamente: é a metonímia que torna possível a metáfora. condensação, é a estrutura de sobreimposição dos significantes onde a metáfora se origina

deslocamento, (...) essa virada da significação que a metonímia demonstra $\mathrm{e}$ que, desde seu aparecimento em Freud, é apresentada como o meio mais eficaz de que dispõe o inconsciente a fim de burlar a censura (LACAN, 1978: 242).

O "simbolismo que se exprime na metáfora supõe a similaridade, a qual é manifestada unicamente pela posição". Lacan alerta, no entanto, que não se pode não considerar a dimensão sintática, pois a palavra (tomada por seu simbolismo) "perderia toda espécie de sentido se baralhássemos as palavras em sua ordem."

"Eis o que se neglicencia quando se fala de simbolismo -a dimensão ligada à existência do significante, a organização do significante (LACAN, 1985: 250).

A centelha criadora da metáfora não jorra da apresentação de duas imagens, isto é, de dois significantes igualmente atualizados. Ela jorra entre dois significantes dos quais um substituiu o outro tomando-lhe o lugar na cadeia significante, o significante oculto permanecendo presente pela sua conexão (metonímica) com o resto da cadeia (LACAN, 1978: 237).

Um novo conceito foi aí introduzido, peguemos sua definição. Cadeia significante: "anéis formando um colar que se enlaça no anel de um outro colar feito de anéis". "De 
onde o poder-se dizer que é na cadeia do significante que o sentido insiste; mas que nenhum dos elementos da cadeia consiste na significação da qual ele é capaz no momento mesmo" (LACAN, 1978: 232). Ou seja, o autor aponta a recorrência do sintoma e a correlação metáfora/metonímia. Não é nem uma nem outra isoladamente, mas a relação entre elas. Volto ao autor:

a estrutura metonímica, indicando que é a conexão do significante com o significante, que permite a elisão pela qual o significante instala a carência do ser na relação de objeto, servindo-se do valor de remessa da significação para investi-la com o desejo visando essa carência que ele suporta.

\section{$[\ldots]$}

a estrutura metafórica, indicando que é na substituição do significante ao significante que se produz um efeito de significação que é de poesia ou de criação, em outras palavras, de advento da significação em questão (LACAN, 1978: 246).

Consideremos, sob um outro viés, o papel de destaque do significante. Slavoj Zizek compara-o em Marx e Freud (o fetiche da mercadoria e o fetiche do sonho), só que o autor alerta-nos de que "a questão é evitar o fascínio propriamente fetichista do 'conteúdo' supostamente oculto por trás da forma: o 'segredo' a ser revelado pela análise não é o conteúdo oculto pela forma (...), mas, ao contrário, o 'segredo' dessa própria forma" (1996: 297). Isto é, o essencial não é o que está latente, e sim os mecanismos de deslocamento e condensação que configuram as formas (das palavras, dos sonhos, das mercadorias, ou seja, dos signos em si).

A estrutura é sempre tríplice; há sempre três elementos em ação: o texto manifesto do sonho, o conteúdo latente do sonho, ou seu pensamento latente, e o desejo inconsciente articulado num sonho. Esse desejo, [...] consistindo inteiramente nos mecanismos do significante, $[. .$.$] seu único lugar está na forma do$ "sonho" [...] (ZIZEK, 1996: 299).
Vejamos como são definidas as instâncias do simbólico, do imaginário e da fantasia.

O Simbólico é utilizado por Lacan em duas direções diferentes e complementares:

a) Para designar uma estrutura cujos elementos discretos funcionam como significantes (modelo linguístico) ou, de um modo mais geral, o registro a que pertencem tais estruturas (a ordem simbólica);

b) Para designar a lei que fundamenta esta ordem: assim Lacan, pela expressão "pai simbólico" ou "nome-do-pai", tem em vista uma instância que não é redutível às metamorfoses do pai real ou imaginário e que promulga a lei (LAPLANCHE, PONTALIS, 1986: 625).

Tentar entender o simbólico separadamente é, de certa maneira, ir contra as próprias ideias de Lacan, pois para ele um significante nunca tem uma ligação fixa com um significado. O simbólico, como já dito anteriormente, compõe a tríade (junto com o real e com o imaginário) que vai compor a realidade.

Deve-se considerar a noção de imaginário sabendo que Lacan, ao usá-la, tinha como referência seu estudo a respeito do "estádio do espelho", no qual o ego da criança começa a se constituir a partir da imagem do seu semelhante. Pode-se, assim, qualificar de imaginário:

a) do ponto de vista intrassubjetivo: a relação fundamentalmente narcísica do indivíduo com seu ego;

b) do ponto de vista intersubjetivo: uma relação chamada dual baseada em -e captada por- a imagem de um semelhante (atração erótica, tensão agressiva). Para Lacan existe semelhante -outro que seja ego- apenas porque o ego é originalmente outro;

[...]

c) quanto às significações: um tipo de apreensão em que certos fatores como a semelhança e o homeoformismo desempenham um papel determinante, o que atesta uma espécie de coalescência [junção de partes que estavam separadas] do significante para o significado (LAPLANCHE, PONTALIS, 1986: 304). 
Em relação à fantasia -que alguns autores não distinguem de "fantasma"-, Lacan a relaciona diretamente ao imaginário. Seria uma espécie de encenação imaginária na qual o desejo está presente, porém de forma defensiva, ou seja: fantasia ou desejo inconsciente seria uma estrutura apenas subjacente a um conteúdo manifesto.

Toda essa discussão aponta para questões que buscam revelar o indivíduo, seus desejos e expectativas. O que significa ser um sujeito? Como se tornar um sujeito (cujo fracasso leva á psicose)? Como promover uma 'precipitação da subjetividade'?

Pela teoria lacaniana, a subjetividade emerge das relações consciente-inconsciente e das relações Eu-Outro. O inconsciente é o discurso do outro; o Outro como linguagem; e também: o Outro como demanda, como desejo (objeto a), como gozo. O eu é o outro imaginário (eu ideal) e o Outro como desejo (o ideal do eu).

Para Lacan, o objeto do desejo ("objeto a") é a causa que perturba o funcionamento das estruturas e que conduz a enigmas. Entendendo o objeto como causa do desejo e não como aquilo capaz de satisfazer o desejo. E a psicanálise, como a entende Lacan, não é um discurso ou fundamento científico; mas algo que permitiria analisar a própria estrutura e funcionamento de outras "disciplinas", propiciando uma visão sobre suas molas mestras e pontos cegos.

A base da psicanálise lacaniana dáse a partir da linguagem (enquanto sistema significante). O discurso não possui uma só dimensão; são vários os discursos presentes ao mesmo tempo. Como esclarece Bruce Fink no livro $\mathrm{O}$ sujeito lacaniano, o $\mathrm{Eu}$ acha que comanda a realidade; o $\mathrm{Eu}$ "acredita que sabe o que pensa e sente, e acredita que sabe por que faz o que faz" (1998: 20).

Por que a ênfase nos lapsos? Por que atribuir importância a esse(s) outro(s) discurso(s) - o Outro como discurso - que irrompem e interrompem o discurso do eu?

Trata-se de procurar um método de elucidação da lógica que governa essas interrupções, e a partir daí (de uma aproximação do seu entendimento) afetar o Outro discurso e, então, provocar a mudança. O Outro é um intruso que transforma nossos desejos, mas ao mesmo tempo, é aquilo que nos capacita a revelar uns aos outros desejos e nos "comunicarmos" (cf. FINK, 1998: 23).

Para Lacan, as noções linguísticas de metáfora e metonímia correspondem aos conceitos freudianos de deslocamento e condensação típicos do sonho. É o que ele denomina de 'alienação do homem na linguagem', pois a linguagem embora permita que o desejo se realize, dá um nó nesse lugar de modo que podemos desejar e não desejar a mesma coisa, e nunca nos satisfazemos.

É, pois, na e a partir da linguagem que podemos revelar/flagrar esses discursos: discurso do eu / discurso do outro; quando o primeiro é consciente, intencional, alienado pela linguagem e o segundo é inconsciente, involuntário, se vale da equivalência literal (por isso a ênfase no significante).

Lacan refuta qualquer teoria linguística estritamente referencial. Para ele, nenhuma palavra tem qualquer valor fixo (exceto em contextos específicos), o que vale é a cadeia de palavras. Enquanto o pensamento se baseia no domínio de sentido, os processos inconscientes não. A análise implica em um processo significativo de decifração que resulta em verdade, não em sentido.

$\mathrm{O}$ autor propõe três esferas:

Real: seria, se fosse possível, um tempo pré-simbólico, pré-linguístico; caracterizase então como um "tecido inteiro, indiferenciado", sem brechas. Aquilo que não foi ainda simbolizado.

Ordem simbólica: lugar de onde parte o pensamento; é aquilo que busca a "divisão do real em zonas separadas, características distintas e estruturas contrastantes", e ao fazê-1o, "ao neutralizar o real, o simbólico cria a 'realidade" " (FIN K, 1998: 44).

Realidade: aquilo que é nomeado pela linguagem e, então, sujeito ao pensamento (simbólico).

O sujeito lacaniano (um significante de um sujeito) pode ser encontrado a partir dos enunciados, ou seja, do que é dito. Sua estruturação, a estruturação da identidade, precisa da interdição. Enquanto sujeito desejante, nossa pulsão é na direção do gozo pleno, da satisfação plena dos desejos (o que é inalcançável, pois levaria à "morte

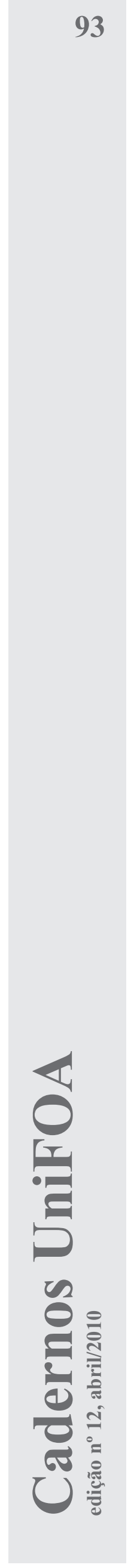


do sujeito"). É na/da interdição (que Lacan coloca na "figura do pai", do "pai" simbólico) que conseguimos nos realizar como sujeito. Sujeito barrado (ou dividido, interditado).

"A divisão é, em certo sentido, a condição da possibilidade da existência de um sujeito e o deslocamento intermitente parece ser sua realização" (FINK, 1998: 70).

E é na alienação - a criança assujeitada ao Outro- que o sujeito (ainda em criança) inserese na linguagem, permitindo que o significante a substitua. Essa substituição (que na criança se dá quando da substituição do desejo da mãe por um nome (via linguagem), caracteriza o que Lacan denomina Nome-do-Pai_ (o não do Pai; a proibição; o falo; o significante do desejo do Outro, desejo da mãe).

\begin{abstract}
"O resultado dessa substituição ou metáfora é o advento do sujeito como tal, o sujeito como não mais apenas uma potencialidade, um mero marcador de lugar no simbólico, esperando ser preenchido, mas um sujeito desejante" (FINK, 1998: 81).
\end{abstract}

Por fim, e reside aí a importância da Fantasia, do Imaginário, flagrar o inconsciente é penetrar nessa ilusão de totalidade; "ao apegar-se ao objeto a, o sujeito é capaz de ignorar sua divisão", esclarece Bruce Fink (1998: 83).

Meu propósito é a utilização das reflexões tecidas anteriormente como estratégia metodológica para tentar captar, na fantasia que alimenta a modernidade, a falácia ideológica.

É necessário, como evidencia Walter Benjamin, "escovar a história a contrapelo", significando com isso a recusa da ilusão/ fantasia de progresso, ou seja, não nadar no sentido da corrente, que, neste caso, seria a crença no desenvolvimento técnico ilimitado.

Evidentemente, Benjamin não nega que os conhecimentos e as atitudes humanas progrediram $[\ldots]$, o que ele recusa [...] é o mito [...] de um progresso da própria humanidade que resulta necessariamente das descobertas técnicas, do desenvolvimento das forças produtivas, da dominação sobre a natureza (LÖWY, 1990: 192).

A crítica de Benjamin sobre a modernidade apoia-se, também, nas análises de Marx em O Capital, pelas quais o mal não está no desenvolvimento técnico em si, mas no uso capitalista que dele advém. Ao invés da máquina possibilitar tempo livre para que o homem (o trabalhador) dedique-se, também, a outras atividades (artísticas, científicas,...), ela o leva a ser explorado ainda mais. Para operar a máquina, o homem tem que "adaptar seu movimento ao movimento contínuo e uniforme do autômato". Poderíamos dizer que não apenas os movimentos, mas também as ideias e a própria criatividade passou, cada vez mais, a apresentar essa característica de automação.

Remetamo-nos a Le Corbusier e sua noção da casa como uma "máquina de morar" e chegaremos a essa mesma automação. Creio, não restam dúvidas de que tal ideia corrobora o anonimato da vida urbana moderna. E além. Vejamos a citação de Lacan, que relaciona o inconsciente a uma "máquina de pensar", onde "a máquina rege o próprio regente":

É numa memória, [...] nossas modernas máquinas para pensar [...], que jaz esta cadeia que insiste em se reproduzir na transferência, e que é a de um desejo morto.

É a verdade do que esse desejo foi em sua história, que o sujeito grita pelo seu sintoma [...] (LACAN, 1978: 249).

Resta-nos tentar entender (aclarar) o que, ou quem, manipula, por detrás do autômato, os efeitos (produtos) das máquinas.

Voltando a Löwy, "a perda da experiência está, assim, para Benjamin, estreitamente ligada à transformação em autômatos: os gestos repetitivos, vazios de sentido [...]" (1990: 194), característica do "mundo (capitalista) moderno. Dominado pela mercadoria, este é o universo por excelência da repetição, do 'sempre-o-mesmo', disfarçado em novidade [...]” (LÖWY, 1990: 198). 
Para Benjamin, em 1940, “a ideia de um progresso da humanidade na história é inseparável da ideia de sua marcha no interior de um tempo vazio e homogêneo. A crítica da ideia do progresso tem como pressuposto a crítica da ideia dessa marcha" (BENJAMIN, 1987, V. 1: 222-232).

Por isso é preciso nadar contra a correnteza, é preciso "escovar a história a contrapelo", e, creio, a maneira mais eficaz é desmistificar a fantasia ideológica inconsciente.

\section{BIBLIOGRAFIA CITADA:}

BAKHTIN, Mikail. Marxismo e filosofia da linguagem. São Paulo : HUCITEC, 1986. BENJAMIN, Walter. Obras escolhidas. São Paulo : Brasiliense, 1987. V.1: Magia e técnica, arte e política : ensaios sobre literatura e história da cultura.

CERQUEIRA FILHO, Gisálio. Análise social da ideologia. São Paulo : EPU, 1988.

DUCROT, Oswald, TODOROV, Tzetan. Dicionário das Ciências da linguagem. Lisboa : Dom Quixote, 1974.

ECO, Umberto. Os limites da interpretação. São Paulo : Perspectiva, 1995.

FINK, Bruce. O sujeito lacaniano : entre a linguagem e o gozo. Rio de Janeiro : Jorge Zahar Ed., 1998.

FOUCAULT, Michel. A ordem do discurso. São Paulo : Loyola, 1996.

KATZ, Chaim Samuel, DORIA, Francisco Antônio, LIMA, Luiz Costa. Dicionário Crítico de Comunicação. Rio de Janeiro : Paz e Terra, 1971.

LAPLANCHE, J., PONTALIS, J. B. Vocabulário da Psicanálise. São Paulo : Martins Fontes, 1986.

LACAN, Jacques. Escritos. São Paulo : Perspectiva, 1978.
O Seminário. Rio de Janeiro :

Jorge Zahar Ed., 1985. Livro 3: As psicoses.

LÖWY, Michel. Romantismo e messianismo : ensaios sobre Lukács e Benjamin. São Paulo : Perspectiva, 1990.

RODRIGUES, Luiz Augusto F. O sentido da falta no discurso. In: XXX CONGRESSO BRASILEIRODELÍNGUAELITERATURA, 1998, Rio de Janeiro. Paper.

- Universidade e a fantasia moderna : a falácia de um modelo espacial único. Niterói : EdUFF, 2001.

ZIZEK, Slavoj. Eles não sabem o que fazem : o sublime objeto da ideologia. Rio de Janeiro : Jorge Zahar Ed., 1992.

. O mais sublime dos histéricos

: Hegel com Lacan. Rio de Janeiro : Jorge Zahar Ed., 1991.

(Org.). Um mapa da ideologia. Rio de Janeiro : Contraponto, 1996.

Contraponto, 1996. p. 297-331: Como Marx inventou o sintoma. - Rio de Janeiro : Contraponto, 1996. p. 7-38: Introdução : o espectro da ideologia.

Endereço para Correspondência:

Luiz Augusto F. Rodrigues

luizaugusto@gmail.com

UFF - Instituto de Artes e Comunicação Social

Rua Lara Vilela, 126 - sala B-101

São Domingos - Niterói / RJ

CEP 24.210-590 